\title{
Simultaneous Recovery of Display Panel Waste Glass and Wastewater Boron by Chemical Oxo-precipitation with Fluidized- Bed Heterogeneous Crystallization
}

Cheng-Kuo Tsai, ${ }^{\dagger \neq}$ Nien-Tsu Lee, ${ }^{\ddagger}$ Gaw-Hau Huang, ${ }^{\ddagger}$ Yoshikazu Suzuki, ${ }^{\S}$ and Ruey-an Doong*,†॰

${ }^{\dagger}$ Department of Biomedical Engineering and Environmental Sciences, National Tsing Hua University, 101, Sec. 2, Kuang Fu Road, Hsinchu 30013, Taiwan

${ }^{\ddagger}$ Department of Chemical Analysis, Industrial Technology Research Institute (ITRI), Hsinchu 30011, Taiwan

${ }^{\S}$ Faculty of Pure and Applied Sciences, University of Tsukuba, Ibaraki 305-8573, Japan

Supporting Information

\begin{abstract}
Silica-based carrier is a promising material for recovery of metal and nonmetal contaminants in chemical oxo-precipitation-fluidized bed crystallization (COP-FBC) system. Boron species are an essential element for plant growth and can cause health concerns in human beings at high concentrations in water environments. The composition of thin-film transistor liquid crystal display (TFT-LCD) contains a wide variety of metal oxides and can be tailored as promising functional mesoporous carriers for boron crystallization recovery in the presence of barium ions and hydrogen peroxide. In this study, waste-derived mesoporous aluminosilicate (MAS) nanomaterial in the presence of barium ions and hydrogen peroxide was used as a carrier for sustainable recovery of crystallized boron, a priority wastewaters pollutant. The MAS shows the hierarchically homogeneous distribution of nanostructured aluminosilicate particles with an average size

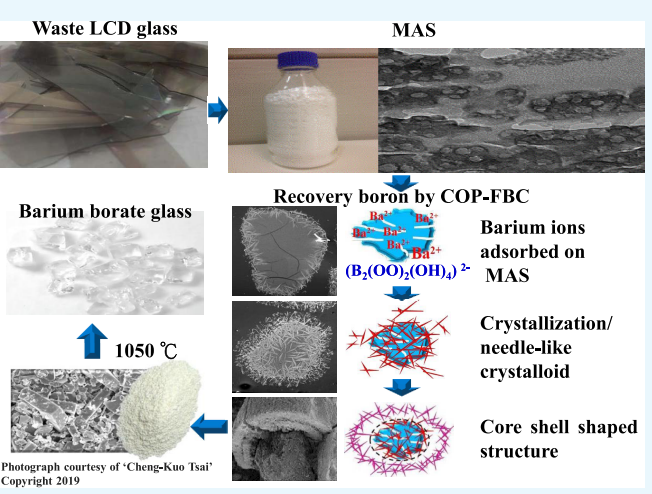
of $12.8 \pm 3.6 \mathrm{~nm}$ on the surface after the activation with $\mathrm{Na}_{2} \mathrm{CO}_{3}$ at $1000{ }^{\circ} \mathrm{C}$. Moreover, the negatively charged surface and the mesoporous structure of MAS enhance the adsorption of $\mathrm{Ba}^{2+}$ onto MAS, and the Langmuir adsorption capacity of $105 \mathrm{mg} / \mathrm{g}$ is achieved, which is conducive to the enhancement of the recovery of boron species. Moreover, the recovery efficiency and crystallization ratio of boron by MAS can be up to 84.5 and $93.4 \%$, respectively. The cross-sectional scanning electron microscopy images and the high-temperature X-ray diffraction results confirm the boron recovery mechanism that the negatively charged functional group as well as the mesoporosity of MAS triggers the rapid formation of needle-shaped precipitates of barium peroxoborate, and then converted to barium borate after calcination at $1050{ }^{\circ} \mathrm{C}$. Results obtained in this study clearly demonstrate the possibility of fabricating environmentally benign mesoporous aluminosilicate adsorbents from TFT-LCD waste to sustainably recover and crystallize boron species from water and wastewater in COP-FBC.
\end{abstract}

\section{INTRODUCTION}

Boron (B) is an element with a number of complex compounds such as boric acid, borate, and perborate in hydrosphere and lithosphere. ${ }^{1}$ These compounds are commonly used in a wide variety of industrial purposes and result in increased environmental concerns after their release into water bodies. ${ }^{2,3}$ Usually, highly soluble boron elements are easily associated with charged molecules, making boron species extremely difficult to be harvested from water and wastewater. ${ }^{3}$ Although boron is an essential element for plant growth, the long-term exposure to high concentrations of boron would result in toxic effects on human health such as coronary artery, cardiovascular, and nervous systems. ${ }^{2,4,5}$ Due to its possible hazard on human beings and ecology, boron has been promulgated as a priority pollutant and the guideline level in drinking water is $2.4 \mathrm{mg} / \mathrm{L}$ by the World Health Organization. ${ }^{4,5}$ Consequently, the need of control technology for an effective recovery of boron as well as conversion of precipitates into high-value products gives rise to the development of sustainable technology for boron treatment and recovery.

Over the past decades, several technologies have been employed for the removal of boron species from effluent streams, namely, chemical precipitation, ${ }^{6,7}$ electrocoagulation, ${ }^{8,9}$ ion exchange, ${ }^{10}$ adsorption, ${ }^{11,12}$ chemical oxo-precipitation (COP), ${ }^{13,14}$ and COP with fluidized-bed homogeneous crystallization (COP-FBHC). ${ }^{15} \mathrm{COP}$ is the peroxolysis process of boron species, which combines oxidant and chemical precipitation for precipitate transformation from $\mathrm{BaB}$ $(\mathrm{OH})_{3} \mathrm{OOB}(\mathrm{OH})_{3}$ and $\mathrm{Ba}\left(\mathrm{B}(\mathrm{OH})_{3} \mathrm{OOH}\right)_{2}$ to the crystallized $\mathrm{BaB}(\mathrm{OH})_{2}(\mathrm{OO})_{2} \mathrm{~B}(\mathrm{OH})_{2}$ at room temperature, ${ }^{14-16} \mathrm{COP}$ is an efficient method for the treatment of elevated concen-

Received: June 25, 2019

Accepted: August 2, 2019

Published: August 16, 2019 
Scheme 1. Illustration of the Crystallization Mechanism for the Recovery of Boron Species Using Mesoporous Aluminosilicate (MAS) as a Carrier in a Chemical Oxo-precipitation Fluidized Bed Crystallization (COP-FBC) Reactor ${ }^{a}$

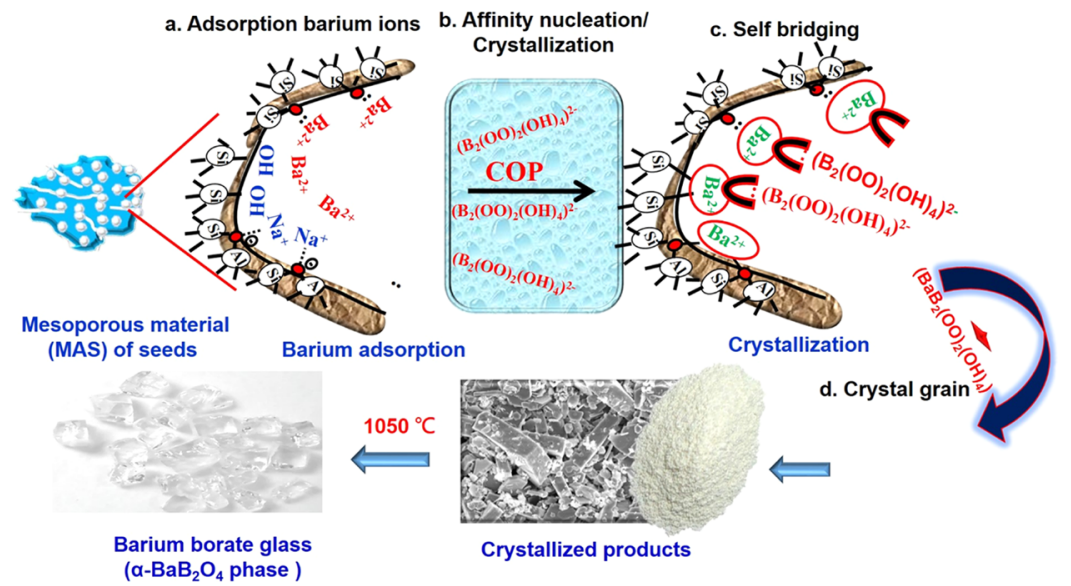

${ }^{a}$ Photograph courtesy of "Cheng-Kuo Tsai”. Copyright 2019.
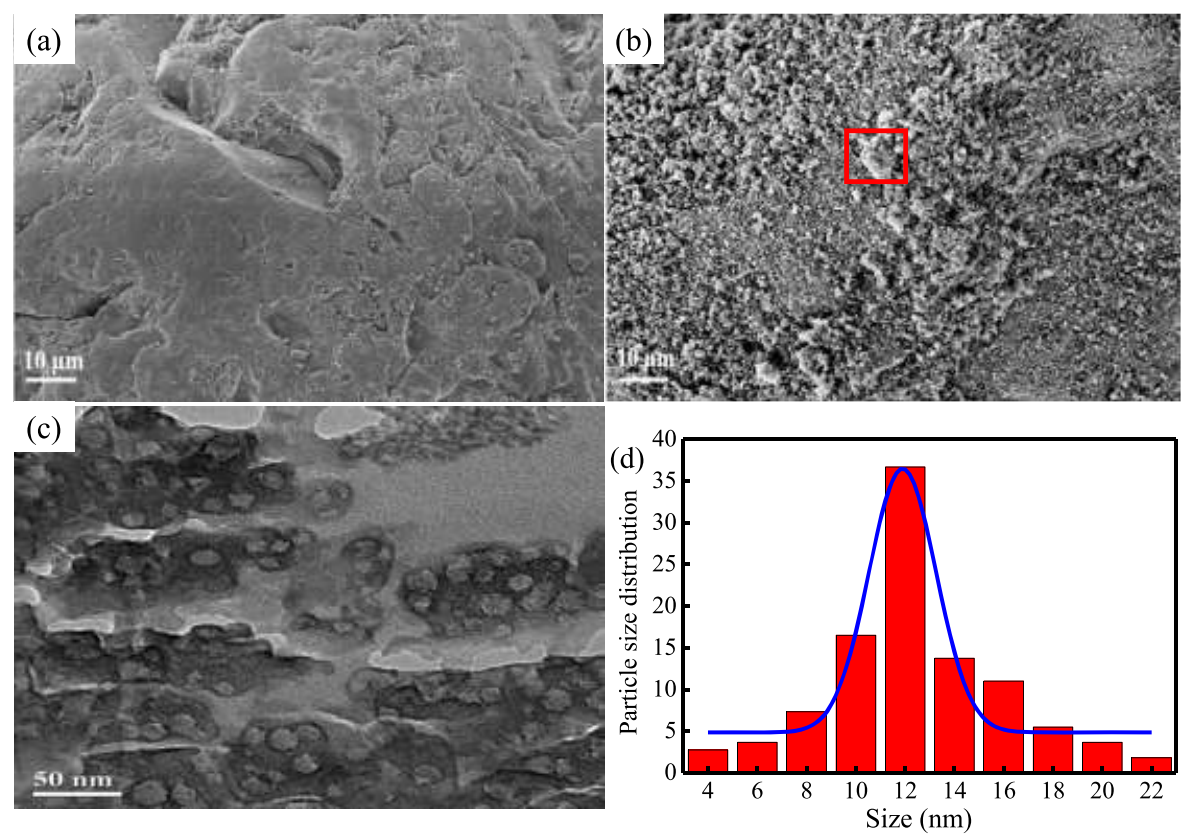

Figure 1. SEM images of (a) silica sand and (b) MAS nanomaterial, (c) cross-sectional FE-TEM image of MAS, and (d) particle size distribution of MAS.

trations of boron in comparison with the chemical precipitation. Usually, the addition of divalent metal salts such as calcium $\left(\mathrm{Ca}^{2+}\right)$, magnesium $\left(\mathrm{Mg}^{2+}\right)$, and barium $\left(\mathrm{Ba}^{2+}\right)$ along with $\mathrm{H}_{2} \mathrm{O}_{2}$ is needed to promote the formation of metal perborate. Barium ions are regarded as the most suitable ions because of the formation of barium perborate. ${ }^{17}$ Although COP and COP-FBHC exhibit good efficiency in the recovery of high concentrations of boron, several challenges including the production of high water content sludge ${ }^{13}$ and the difficulty in the disposal of sludge are experienced because of the homogeneous precipitation process.

To overcome the disadvantage of producing large amounts of sludge, COP with fluidized-bed crystallized (COP-FBC), a heterogeneous crystallization using active silica-based particles as carriers in COP reactor, has been developed to reduce the produced amount of sludge as well as to enhance the crystallization ratio. ${ }^{18,19}$ Several studies have shown that FBC has a good removal and crystallization efficiency on the removal of nonmetal elements such as phosphorous ${ }^{18}$ and fluoride. ${ }^{19}$ However, the sand carriers used in COP-FBC are usually nonporous and have a low surface area, which is relatively difficult in promoting the nucleation for boron recovery in the presence of $\mathrm{Ba}^{2+}$. It is noted that several mesoporous materials including SBA- $15,{ }^{20} \mathrm{MCM}-41,{ }^{21}$ and titanate nanotubes ${ }^{22,23}$ have been used to adsorb divalent metal ions. However, the use of mesoporous materials as carriers for COP-FBC to effectively remove boron as well homogeneously crystallize boron-based precipitates in the presence of divalent metal ions has received less attention. It is therefore imperative to look for cost-effective mesoporous materials as COP-FBC carrier to rapidly recover boron by crystallization of boron species in the presence of barium ions.

TFT-LCD panel contains a high content of valuable material including glass, plastic and precious metals and different 

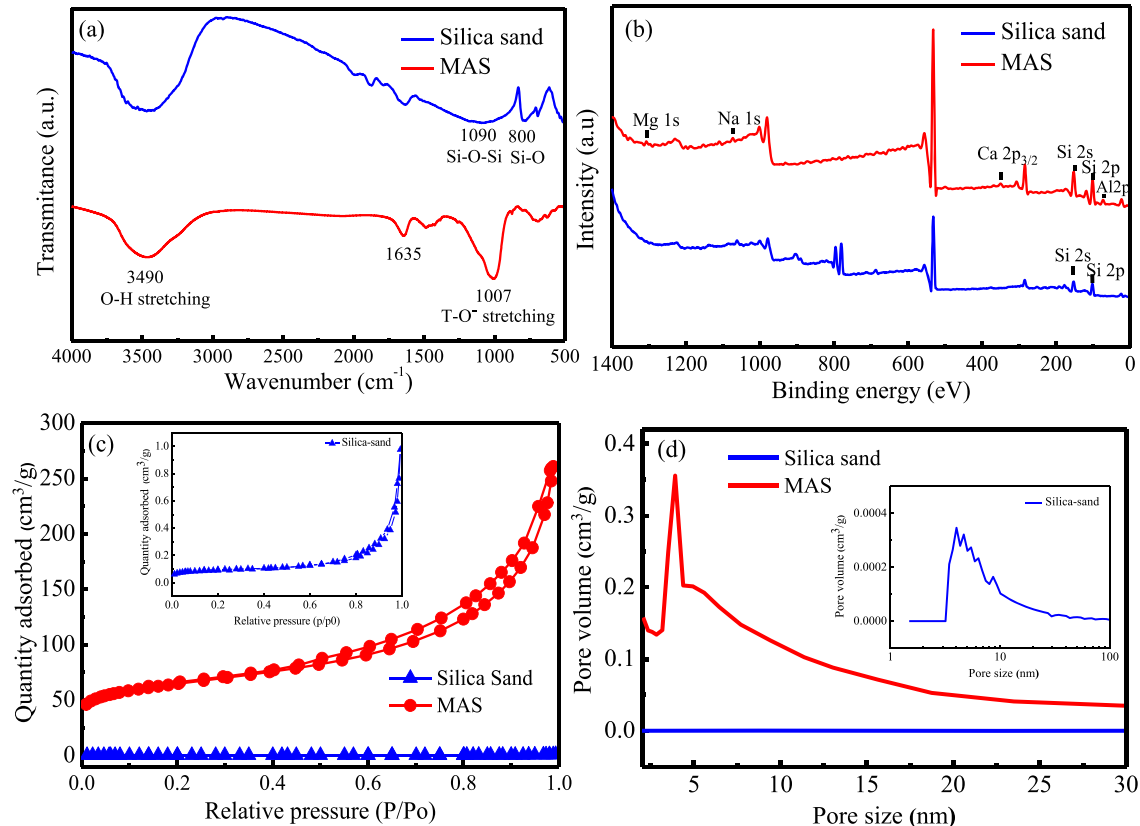

Figure 2. (a) FTIR spectra of silica and MAS, (b) X-ray photoelectron spectra (XPS) of silica and MAS, and (c) $\mathrm{N}_{2}$ adsorption-desorption isotherm and (d) pore size distribution of the commercial silica sand and the as-prepared MAS nanomaterials derived from the waste TFT-LCD. Insets in figure (c) and (d) are the enlarged figures of isotherm and pore size distribution of silica sand, respectively.

approaches for the recovery of glass from end-of-life liquid crystal display $^{24,25}$ such as zeolite ${ }^{26}$ and soda lime silicate glasses. $^{27}$ Usually, TFT-LCD can undergo thermoalkaline treatment and the impurities like metal and metal oxides can be removed by acid washing. ${ }^{28}$ However, the fabrication of silica-based mesoporous materials from TFT-LCD has received less attention. A previous study has indicated that a mesoporous aluminosilicate composite can be prepared from the TFT-LCD waste panel for an effective adsorption of heavy metal ions including $\mathrm{Ni}, \mathrm{Cu}$, and $\mathrm{Zn}^{29}$ Waste-derived mesoporous aluminosilicate (MAS) is environmentally friendly, has a high surface area and a narrow-distributed pore size, and a surface that can be easily tailored. All these features make it a suitable nanomaterial to serve as a COPFBC carrier for the adsorption of $\mathrm{Ba}^{2+}$ as well as for the recovery of boron ion by crystallization of barium perborate, although MAS has never been used for this scope yet.

In this study, the mesoporous aluminosilicate (MAS) nanomaterial fabricated from the waste TFT-LCD panels serves as a carrier of COP-FBC to enhance the adsorption capacity of $\mathrm{Ba}^{2+}$ and the crystallization efficiency of boron. Moreover, the boron-containing precipitates are then calcined to form crystalline materials for the recovery of boron. As shown in Scheme 1, the waste TFT-LCD panel is melted at $1000{ }^{\circ} \mathrm{C}$ in the presence of $\mathrm{Na}_{2} \mathrm{CO}_{3}$ to produce hydroxylfunctionalized MAS, which can enhance the adsorption of $\mathrm{Ba}^{2+}$ by ion exchange. Ba-MAS is then used as a carrier in the COPFBC reactor to provide the crystallization affinity toward boron recovery via the formation of barium peroxoborate (Ba$\left.\mathrm{B}_{2}(\mathrm{OO})_{2}\left(\mathrm{OH}_{4}\right)\right)$ precipitates in the presence of $\mathrm{H}_{2} \mathrm{O}_{2}$. The identification of the crystallized phase change in the morphology of Ba-MAS before and after COP-FBC indicates that boron can be recovered as a high purity of $\mathrm{BaB}_{2} \mathrm{O}_{4}$. Results of this study clearly demonstrate the feasibility of using novel MAS from the waste TFT-LCD panel for the enhanced recovery of boron elements in wastewater, which can open a gateway to design an environmentally friendly treatment technology from the industrial wastes to simultaneously recover metal ions and inorganics.

\section{RESULTS AND DISCUSSION}

Surface Characterization of Silica Sand and MAS. The surface morphologies of commercial silica sand and the asprepared MAS were first characterized and compared by electronic microscopic images. As illustrated in Figure 1a, the scanning electron microscopy (SEM) image of silica sand shows a well-rounded pattern with a smooth, fractured, irregularly cratered, and nonporous surface. The original waste TFT-LCD material shows large fragments with an unmelted and nonporous surface (Figure S1, Supporting Information). This large fragment is mainly from the angular flaky particles within a broad range of particle size after ball milling. ${ }^{30}$ The SEM image of MAS after alkali treatment with $\mathrm{Na}_{2} \mathrm{CO}_{3}$ at $1000{ }^{\circ} \mathrm{C}$ is given in Figure $1 \mathrm{~b}$, which shows many roughly small particles with a multilayered assembly. The particle size of MAS, produced after the alkali and heat treatment, is in the range of $0.2-9.0 \mu \mathrm{m}$. Moreover, the crosssectional field emission transmission electron microscopy (FETEM) images of MAS was further studied from the red box of Figure $1 \mathrm{~b}$ to elucidate the change in surface morphology, and the result is shown in Figure 1c. It is clear that a wide range of nanostructured particles appear on the surface of MAS. In addition, the MAS shows a homogeneous distribution of nanoparticles on the surface, which form a hierarchical structure of aluminosilicate after $\mathrm{Na}_{2} \mathrm{CO}_{3}$ treatment and calcination at $600{ }^{\circ} \mathrm{C}$ for $6 \mathrm{~h}$. As shown in Figure $1 \mathrm{~d}$, the distribution of MAS particles exhibits a narrow particle size range of 4-22 nm with an average lateral size of $12.8 \pm 3.6 \mathrm{~nm}$ $(n=105)$, which indicates that MAS can provide a large specific surface area and pore channel to serve as a superior carrier for the recovery of boron species. It is noted that our previous study also used TFT-LCD to prepare the mesoporous aluminosilicate using the thermoalkaline reaction. The mean 
particle size is $12.1 \pm 3.9 \mathrm{~nm}$ after calcination at $110{ }^{\circ} \mathrm{C}$ for 12 $\mathrm{h},{ }^{29}$ which is similar to the results obtained in this study.

Figure 2a shows Fourier transformation infrared (FTIR) spectra of silica and MAS after the alkali treatment at $1000{ }^{\circ} \mathrm{C}$. The FTIR spectra of silica sand show a broad peak at 3502 $\mathrm{cm}^{-1}$, which is the stretching vibration of the $-\mathrm{OH}$ bond and/ or bending vibration of the adsorbed $\mathrm{H}-\mathrm{O}-\mathrm{H}$ bond from water molecules. ${ }^{31}$ The peak at $1090 \mathrm{~cm}^{-1}$ belongs to $\mathrm{Si}-\mathrm{O}-$ Si stretching, while that at $800 \mathrm{~cm}^{-1}$ in the silica sand spectra belongs to $\mathrm{Si}-\mathrm{O}$ bending. After activation with $\mathrm{Na}_{2} \mathrm{CO}_{3}$, the MAS spectrum also exhibits a strong peak of hydroxyl functional group $(-\mathrm{OH})$ at $3490 \mathrm{~cm}^{-1}$ and that of carbonyl group $(\mathrm{C}=\mathrm{O})$ at $1635 \mathrm{~cm}^{-1}$ in comparison with the silica sand. Another distinct peak located at $1007 \mathrm{~cm}^{-1}$, which belongs to the $\mathrm{T}-\mathrm{O}^{-} \cdots \mathrm{Na}^{+}$bond, is originally derived from the cleavage of $\mathrm{T}-\mathrm{O}-\mathrm{T}^{\prime}$ linkages (where $\mathrm{T}$ and $\mathrm{T}^{\prime}$ is $\mathrm{Si}$ or $\left.\mathrm{Al}\right)^{32}$ at $1095 \mathrm{~cm}^{-1}$ (Figure S2, Supporting Information) after $\mathrm{Na}_{2} \mathrm{CO}_{3}$ activation. $^{33}$ Moreover, the X-ray diffractometer (XRD) patterns of MAS after activation treatment in the presence of $\mathrm{Na}_{2} \mathrm{CO}_{3}$ show several peaks at $13.9,24.3,30.1,34.5,38.1,41.5$, and $42.6^{\circ}$, which can be assigned to the (110), (211), (310), (222), (321), (400), and (411) planes of amorphous sodium aluminum carbonate silicate (ICDD-PDF-00-015-0469) (Figure S3, Supporting Information). The formation of amorphous silicate is mainly attributed to the fact that the aluminoborosilicate of TFT-LCD panel was blended with excess $\mathrm{Na}_{2} \mathrm{CO}_{3}$ during the melting process at a high temperature of $1000{ }^{\circ} \mathrm{C}$.

The surface chemistry of silica sand and the as-prepared MAS was further studied to characterize the change in elemental species. Figure $2 \mathrm{~b}$ shows the scan survey spectra of silica sand and acid-treated TFT-LCD panels of MAS nanomaterials. Several XPS peaks at 102, 153, 284, and 532 $\mathrm{eV}$ appear in the commercial silica sand spectra, which can be assigned to $\mathrm{Si} 2 \mathrm{p}, \mathrm{Si} 2 \mathrm{~s}, \mathrm{C} 1 \mathrm{~s}$, and $\mathrm{O} 1 \mathrm{~s}$, respectively. This result clearly indicates that the silica sand only contains $\mathrm{SiO}_{2}$. The small peak of $\mathrm{C} 1 \mathrm{~s}$ at $284 \mathrm{eV}$ is mainly attributed to trace organic carbons from the atmosphere. Moreover, several additional peaks centered at 74, 347, 1073, and $1304 \mathrm{eV}$ are clearly observed in the MAS spectrum, which are mainly contributed from $\mathrm{Al} 2 \mathrm{p}, \mathrm{Ca} 2 \mathrm{p}, \mathrm{Na} 1 \mathrm{~s}$, and $\mathrm{Mg} 1 \mathrm{~s}$, respectively. The distinct peak of sodium atoms at $1073 \mathrm{eV}$ can be assigned to the $\mathrm{Si}-\mathrm{O}-\mathrm{Na}^{+}$bond. ${ }^{34}$ Our previous study has reported that the $\mathrm{Na}_{2} \mathrm{O}-\mathrm{B}_{2} \mathrm{O}_{3}$ phase can be removed during the activation process, and then the exposure of oxygen atoms would produce $\mathrm{Si}-\mathrm{OH}$ or $\mathrm{Si}-\mathrm{O} \cdots \mathrm{Na}^{+}$functional group after acid washing. ${ }^{29}$ Therefore, the borosilicate TFT-LCD waste can be completely tailored as the sodium aluminosilicate framework of MAS after the activation.

Pore Texture of Aluminosilicate Materials. The pore texture including specific surface areas and pore size distribution of silica sand and MAS was further examined. As illustrated in Figure $2 \mathrm{c}$, the $\mathrm{N}_{2}$ adsorption-desorption isotherm of the silica sand material can be classified as a type III isotherm with a slight hysteresis loop at a relative pressure range $\left(P / P_{0}\right)$ of $0.9-0.95 .^{35}$ In addition, no obvious pore size distribution pattern is observed (Figure $2 \mathrm{~d}$ ). This result clearly indicates the nonporous nature of silica sand, and the hysteresis loop at a high $P / P_{0}$ range is mainly attributed to the interparticle voids of silica sand. In contrast to silica sand materials, the adsorption-desorption isotherm of MAS material follows a type IV physisorption isotherm with an $\mathrm{H} 3$ hysteresis loop in the $P / P_{0}$ range of $0.4-0.98$, which is mainly attributed to the capillary condensation in mesoporous structures. $^{36}$ Moreover, the pore size distribution of MAS exhibits a sharp peak at $3.9 \mathrm{~nm}$ and then follows a broad pore size distribution in the mesoporous region $(2-50 \mathrm{~nm})$. The peak of $3.9 \mathrm{~m}$ is mainly attributed to the hierarchically pore structure of nanoparticles, while the broad distribution is from the voids of the interparticles of MAS. Moreover, the specific surface area is $0.6 \mathrm{~m}^{2} / \mathrm{g}$ for the commercial silica sand and 226 $\mathrm{m}^{2} / \mathrm{g}$ for MAS after the activation from waste TFT-LCD (Table S1, Supporting Information), which indicates that the activated MAS can serve as a potential carrier for COP-FBC treatment.

Adsorption of $\mathrm{Ba}^{2+}$ by MAS. The adsorption efficiency of barium ions by the treated TFT-LCD panel-based material (MAS) was investigated at $\mathrm{pH}$ 5. The selection of a weakly acidic condition is to avoid the precipitation of $\mathrm{Ba}^{2+}$ in solution. Figure 3 shows the adsorption isotherm of $\mathrm{Ba}^{2+}$ by

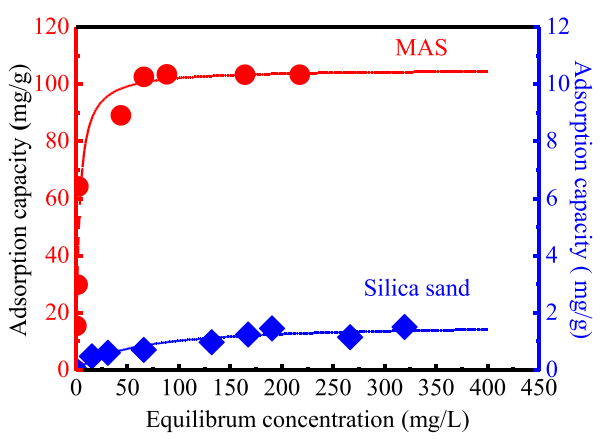

Figure 3. Adsorption isotherms and the fitted Langmuir model of silica sand and MAS for $\mathrm{Ba}^{2+}$ adsorption.

silica sand and mesoporous MAS materials at $25^{\circ} \mathrm{C}$. The silica sand material exhibits little capacity for $\mathrm{Ba}^{2+}$ adsorption, probably attributed to the low specific surface area and the lack of functional groups. On the contrary, the mesoporous MAS material is an excellent adsorbent of $\mathrm{Ba}^{2+}$ in comparison with silica sand. The adsorption of $\mathrm{Ba}^{2+}$ ion by MAS increases dramatically at a low equilibrium concentration of $<50 \mathrm{mg} / \mathrm{L}$ and then levels off to a plateau in a high equilibrium concentration range of $75-250 \mathrm{mg} / \mathrm{L}$.

The adsorption behavior of divalent metal ions onto mesoporous material can be described by Langmuir and Freundlich isotherm models. ${ }^{37}$ Table 1 shows the fitted

Table 1. Isothermal Parameters of $\mathrm{Ba}^{2+}$ Adsorption onto the Silica Sand and MAS Materials

\begin{tabular}{lccccccc} 
& \multicolumn{3}{c}{ Langmuir model } & & \multicolumn{3}{c}{ Freundlich model } \\
\cline { 2 - 4 } material & $\begin{array}{c}q_{\max } \\
(\mathrm{mg} / \mathrm{g})\end{array}$ & $\begin{array}{c}K_{\mathrm{d}} \\
(\mathrm{L} / \mathrm{mg})\end{array}$ & $R^{2}$ & & $K_{\mathrm{f}}$ & $n$ & $R^{2}$ \\
silica sand & 1.83 & 0.333 & 0.919 & & 3.37 & 161 & 0.864 \\
MAS & 105 & 0.014 & 0.999 & & 4.36 & 3.71 & 0.863 \\
\hline
\end{tabular}

parameters of Langmuir and Freundlich models. The Langmuir isotherm model can accurately describe the adsorption of $\mathrm{Ba}^{2+}$ by MAS mesoporous material, and the correlation coefficient $\left(R^{2}\right)$ is $>0.995$. Moreover, the maximum adsorption capacity of $\mathrm{Ba}^{2+}$ is $105 \mathrm{mg} / \mathrm{g}$. A previous study has used the surfacemodified 2D titanium carbide to enhance the adsorption of barium ions, and the adsorption capacity of $\mathrm{Ba}^{2+}$ was $46.5 \mathrm{mg} /$ $\mathrm{g}^{38}$ clearly indicating the superior ability of the developed MAS nanomaterials toward metal ion adsorption. 

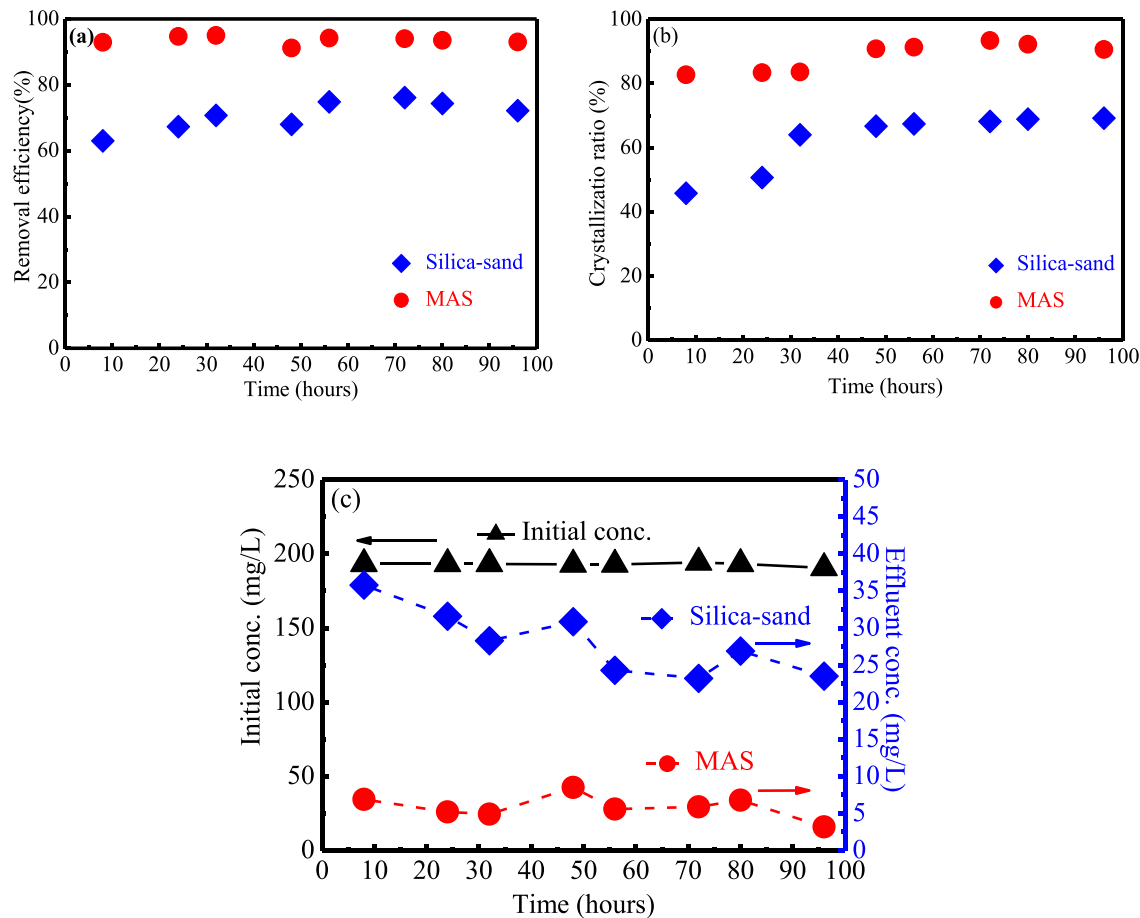

Figure 4. Comparison of the boron recovery performance of silica sand and MAS in terms of (a) removal efficiency, (b) crystallization ratio, and (c) effluent concentration as the function of reaction time in the COP-FBC process at $\mathrm{pH} 10.5$.

Table 2. Comparison of the Recovery Efficiency and Crystallization Ratio of Boron Using COP-Based Treatment Processes

\begin{tabular}{lccclc}
\hline methods & {$[B]_{\text {in }}(\mathrm{mg} / \mathrm{L})$} & removal efficiency $(\%)$ & crystallization ratio (\%) & $\mathrm{pH}$ & \multicolumn{1}{c}{ references } \\
COP & 1000 & 98.5 & $a$ & 10 (batch) & 10.5 (batch) \\
COP & 1000 & 99.7 & & 11 (batch) & 14 \\
COP & 1000 & 87 & & 11 (column) & 15 \\
FBHC & 1000 & 96.6 & 60 & 10.5 (column) \\
FBC-silica sand & 200 & 76.5 & 63 & & this study \\
FBC-MAS & 200 & $94.8^{b}$ & 93.4 & \\
& 200 & $84.5^{c}$ & 93.4 &
\end{tabular}

${ }^{a}$ No crystallization occurred. ${ }^{b}$ Recovery that does not take into account the boron produced from the activation of TFT-LCD. ${ }^{c}$ Recovery that takes into account the boron produced from the activation of TFT-LCD.

The high adsorption efficiency of $\mathrm{Ba}^{2+}$ by MAS can be attributed to the high mesoporosity and the functionalization of MAS during the activation process, which can not only produce a mesoporous structure for the removal of $\mathrm{Na}_{2} \mathrm{O}-$ $\mathrm{B}_{2} \mathrm{O}_{3}$ phase structure but also increase the functional groups and electrostatic sites for $\mathrm{Ba}^{2+}$ adsorption. The negatively charged functional groups on the surface of aluminosilicate $\left(\mathrm{T}-\mathrm{O}^{-}\right)$can be counter-balanced by the addition of $\mathrm{Na}^{+}$ cations from the activation agent of $\mathrm{Na}_{2} \mathrm{CO}_{3}$ to form $\mathrm{T}-\mathrm{O}^{-} \ldots$ $\mathrm{Na}^{+}$clusters. ${ }^{29}$ Besides, $\mathrm{Ca}^{2+}$ and $\mathrm{Mg}^{2+}$, serving as charge compensators of $\mathrm{AlO}_{4}^{-}$clusters, would migrate into the aluminosilicate surface when the $\mathrm{Al}$-containing tetrahedral network is ruptured. ${ }^{32}$ Therefore, the negatively charged surface and mesoporous structure of MAS enhance the adsorption of $\mathrm{Ba}^{2+}$ onto MAS, which may provide high affinity toward the nucleation of barium peroxoborate precipitate during the boron recovery in the COP-FBC process.

Boron Recovery by COP-FBC. Since the adsorbed $\mathrm{Ba}^{2+}$ onto the MAS may increase the crystallization of borate precipitates, the recovery efficiency as well as the crystallization ratio of boron by silica sand and MAS was used to evaluate the performance of COP-FBC process on boron recovery at the
$\left[\mathrm{H}_{2} \mathrm{O}_{2}\right] /[\mathrm{B}]$ and $[\mathrm{Ba}] /[\mathrm{B}]$ ratios of 2 and 1 , respectively, at $\mathrm{pH}$ 10.5. Figure $4 \mathrm{a}$ shows the recovery efficiency of boron by silica sand and MAS as a function of reaction time in the COP-FBC process. It is clear that the recovery efficiency of boron by the commercial silica sand increases slightly from $62.9 \%$ at $10 \mathrm{~h}$ of incubation to $76.1 \%$ at $100 \mathrm{~h}$. The MAS exhibits a better and stable recovery efficiency of boron, and the efficiency of 91.2$94.8 \%$ is observed after $100 \mathrm{~h}$ of incubation.

The crystallization ratio also shows a similar trend. As illustrated in Figure $4 \mathrm{~b}$, the crystallization ratio of boron increases from $45.8 \%$ at $10 \mathrm{~h}$ to $69.2 \%$ at $100 \mathrm{~h}$ by silica sand, while the crystallization ratio of $82.7-93.4 \%$ is observed when MAS was used as the carrier. A previous study has used the COP-FBC process to recover boron in the absence of a carrier and obtained a crystallization recovery of around $60 \% .{ }^{15}$ In this study, the high crystallization ratio of boron ions is mainly attributed to the high surface area of MAS and the high adsorbed amount of $\mathrm{Ba}^{2+}$ onto the surface, which can easily facilitate the nucleation and subsequently results in fast crystallization within $10 \mathrm{~h}$. Therefore, the high crystallization property of MAS adsorbents produces less sludge in comparison with the commercial silica sand. In addition, the 

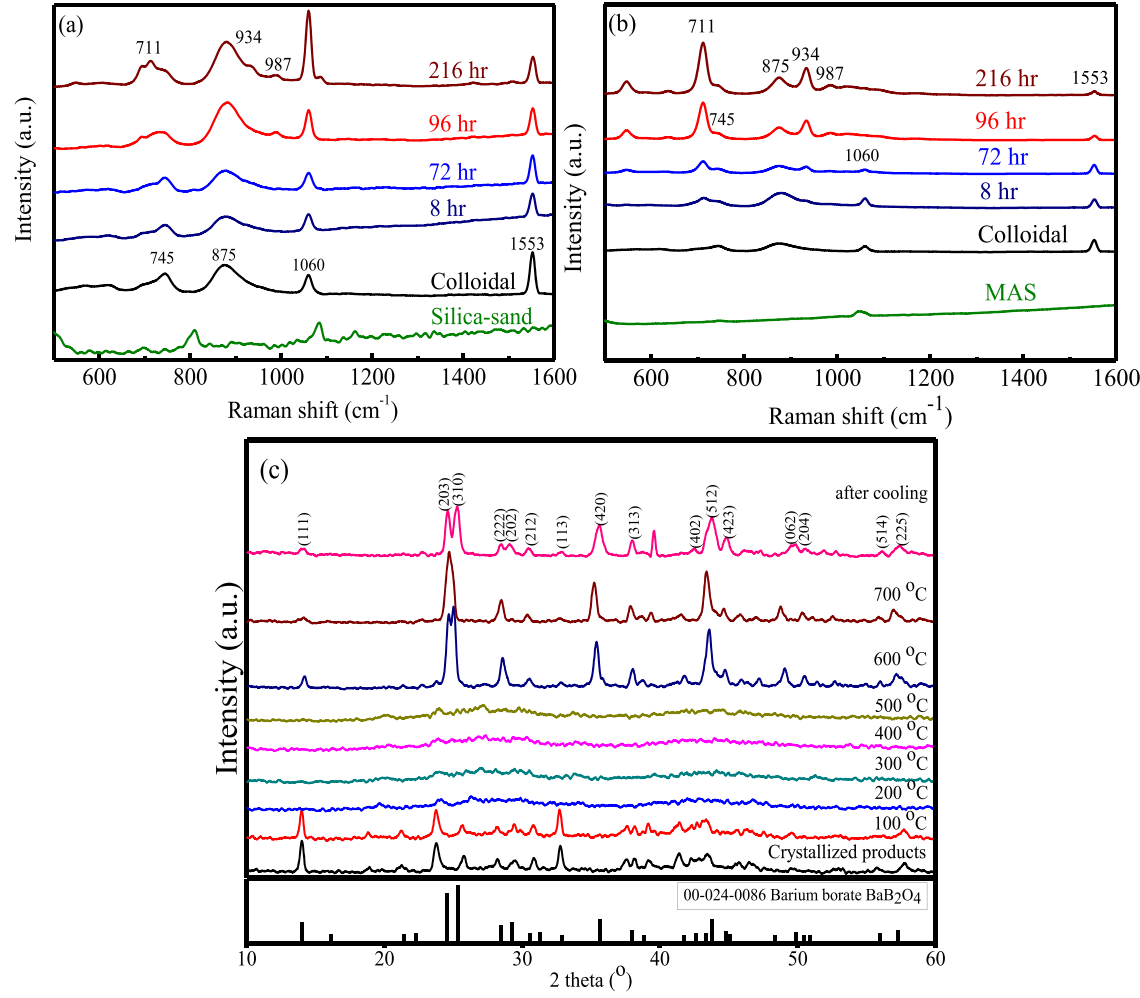

Figure 5. Raman spectra of the precipitates produced from the recovery of boron in the presence of (a) silica sand and (b) MAS as a function of reaction time. (c) HT-XRD patterns for crystallized products by MAS carrier in COP-FBC after $216 \mathrm{~h}$ of incubation.

boron concentration in the effluent can be maintained at a relatively low level in the presence of MAS. As shown in Figure $4 \mathrm{c}$, the boron concentration in the effluent of the COP-FBC process decreases from $35.8 \mathrm{mg} / \mathrm{L}$ at $10 \mathrm{~h}$ to $23.5 \mathrm{mg} / \mathrm{L}$ at 100 h. In contrast, the boron concentration in the effluent decreases rapidly to $6.5 \mathrm{mg} / \mathrm{L}$ in the first $10 \mathrm{~h}$ and then maintains at the similar concentration after $100 \mathrm{~h}$ of incubation, clearly demonstrating the superiority of MAS for boron recovery and crystallization.

A wide variety of COP processes including pure COP and COP-FBHC in the absence of a carrier have been used to remove/recover boron in aqueous solutions. ${ }^{14,15,17}$ Table 2 compares the recovery efficiency and crystallization ratio of boron with the reported results. Lin et al. investigated the effectiveness of boron recovery by COP using $\mathrm{H}_{2} \mathrm{O}_{2}$ and barium ions as promoters ${ }^{14}$ and found that peroxoborate precipitates were transformed from the amorphous BaB$(\mathrm{OH})_{3} \mathrm{OOB}(\mathrm{OH})_{3}$ and $\mathrm{Ba}\left(\mathrm{B}(\mathrm{OH})_{3} \mathrm{OOH}\right)_{2}$ to the crystalline $\mathrm{BaB}(\mathrm{OH})_{2}(\mathrm{OO})_{2} \mathrm{~B}(\mathrm{OH})_{2}$. $\mathrm{Vu}$ et al. used COP-FBHC to reclaim boron as the calcium perborate pellets to minimize the production of sludge and calculated the crystallization ratio to be around $60 \%{ }^{15}$ Moreover, Shih et al. added $\mathrm{H}_{2} \mathrm{O}_{2}$ into the COP system to promote the treatment efficiency of boric acid in the presence of barium ions and obtained an enhanced boron removal efficiency of $98.5 \% .{ }^{17}$ Although good recovery efficiency of boron by COP-FBHC is observed, the crystallization ratio is not high and a large amount of sludge is produced, which needs further treatment and recycling.

In this study, the addition of MAS into the COP-FBC reactor shows a similar recovery efficiency of boron but a high crystallization ratio in comparison with those reported for COP and COP-FBHC processes, ${ }^{14,15}$ clearly indicating that MAS is an excellent carrier to promote the precipitation of borate species as well as to enhance the crystallization ratio. The high crystallization ratio can be attributed to the high porosity and functionalization of MAS materials during the activation process, which enhance the ion exchange and electrostatic attraction sites to facilitate a strong interaction between barium ions and diperoxodiborate dianion $\left(\mathrm{B}_{2}(\mathrm{OO})_{2}(\mathrm{OH})_{4}^{2-}\right)$. Therefore, boron species can be recovered through the formation of barium peroxoborate. It should be noted that the original TFT-LCD glass contains boron as $\mathrm{N}_{2} \mathrm{O}-\mathrm{B}_{2} \mathrm{O}_{3}$, which is washed away during the activation process. Therefore, MAS itself would produce certain amount of boron that is supposed to be recovered by COP-FBC. This decreases the recovery of boron by COP-FBC from $94.8 \%$ originally to $84.5 \%$ when taking into account the total washed amount of boron from TFT-LCD. Since the boron species in COP-FBC will be recovered and crystallized, the MAS can, therefore, be recycled and reused for the sustainable removal of boron from wastewater.

Identification of Peroxoborate Precipitates. Since boron in solution can be reacted with barium ions to form peroxoborate precipitates in the presence of $\mathrm{H}_{2} \mathrm{O}_{2}$, the change in the chemical structure as well as the crystallinity of precipitates at various reaction times was further identified using Raman spectroscopy and high-temperature XRD. Figure $5 \mathrm{a}, \mathrm{b}$ shows Raman spectra of the precipitates produced from reactions based on silica sand and MAS, respectively, at various reaction times. The Raman spectra of the precipitates from the silica sand shows four distinct peaks at 745, 875, 1060, and $1553 \mathrm{~cm}^{-1}$. The peak at $875 \mathrm{~cm}^{-1}$ is the contribution of the symmetric $\mathrm{BO}_{3}$ stretching of $\mathrm{B}(\mathrm{OH})_{3}$ and $\mathrm{O}-\mathrm{O}$ stretching of $\mathrm{H}_{2} \mathrm{O}_{2}{ }^{13,39}$ and the band at $1553 \mathrm{~cm}^{-1}$ is attributed to the $\mathrm{O}-\mathrm{O}$ stretching of oxygen. ${ }^{14,15}$ Bands at 745 and $1060 \mathrm{~cm}^{-1}$ likely arise from the asymmetric $\left[\mathrm{B}(\mathrm{OH})_{4}\right]^{-}$stretching of 
metaborate due to the $v_{1}$ symmetric $(\mathrm{B}-\mathrm{O}(\mathrm{OH}))$ of metaborate $^{14}$ and symmetric $(\mathrm{B}-\mathrm{OH})$ stretching of $\mathrm{H}_{3} \mathrm{BO}_{3}{ }^{40}$ respectively. This means that the precipitate from silica sand is an amorphous perborate and the chemical structure is $\mathrm{B}(\mathrm{OH})_{3}(\mathrm{OOH})^{-} .^{14}$ It is clear that the peak intensities at 875 and $1060 \mathrm{~cm}^{-1}$ increase upon increase in the reaction time, which means an increase in the crystallization of the precipitates with time.

The Raman spectra of the precipitates produced from the MAS system are different from those from silica sand. Although the bands in the Raman spectra of the precipitates produced by MAS are similar to those by silica sand, the crystallization of MAS-based precipitates is more rapid and several sharp peaks at 711,934 , and $987 \mathrm{~cm}^{-1}$ associated with $v_{\text {asym }}\left(\mathrm{B}_{2}(\mathrm{OO})_{2}\right), v_{\text {sym }}(\mathrm{O}-\mathrm{O})$, and $v_{\text {sym }}(\mathrm{B}-\mathrm{O})$ are observed, respectively. ${ }^{14,39}$ In addition, the peak intensity increases with increase in the reaction time from 8 to $216 \mathrm{~h}$, which indicates that the reaction of perborate with peroxo groups produces cyclic dimeric peroxoborate $\left(\mathrm{B}_{2}(\mathrm{OO})_{2}(\mathrm{OH})_{4}\right)^{2-}$ by linking two peroxo bridges with two four-coordinated boron atoms. ${ }^{14,39}$ It is noteworthy that the crystalline structure of barium peroxoborate $\left(\mathrm{BaB}_{2}(\mathrm{OO})_{2}(\mathrm{OH})_{4}\right)$ is rapidly formed in the presence of MAS carrier because of considerable absorbed amounts of barium onto the MAS surface. These results clearly demonstrate the superiority of MAS to rapidly produce crystallized precipitates within $8 \mathrm{~h}$ in comparison with silica sand, which needs $216 \mathrm{~h}$ for crystallization.

To further understand the possible structure of the recovered precipitates, high-temperature XRD (HT-XRD) was further used to in situ identify the change in the crystallization of MAS-based products at various temperatures. As illustrated in Figure 5c, HT-XRD patterns show that the structure of peroxoborate $\left(\mathrm{BaB}_{2}(\mathrm{OO})_{2}(\mathrm{OH})_{4}\right)$ changes from a well-crystallized phase originally to an amorphous phase at $200-500{ }^{\circ} \mathrm{C}$. However, the crystallinity of $\mathrm{BaB}_{2} \mathrm{O}_{4}$ changes again when the samples are sintered to $600{ }^{\circ} \mathrm{C}$. The lattice constants of $a=11.13 \AA, b=12.67 \AA$, and $c=8.38 \AA$ are obtained, which is the $C 2 / c$ space group of $\mathrm{BaB}_{2} \mathrm{O}_{4}$ (ICDDPDF-00-024-0086). In this study, the boron-based precipitate is calcined at $1050{ }^{\circ} \mathrm{C}$ and a glasslike material is obtained, which indicates the formation of $\alpha-\mathrm{BaB}_{2} \mathrm{O}_{4}$ structure.

Crystallization Mechanism. To further elucidate the mechanism of crystallization, the change in the morphology of boron-containing precipitates by silica sand and MAS materials was further examined by cross-sectional SEM. As illustrated in Figure 6, the needle-shaped precipitates of perborate start to accumulate onto the active sites of the MAS surface at $8 \mathrm{~h}$ (Figure 6a) and then almost cover the surface of MAS at $72 \mathrm{~h}$ (Figure $6 \mathrm{~b}$ ). Once the formation of perborate precipitates reaches the saturation of active sites onto the MAS surface, the crystals start to build up the peroxo-bridge and continue to grow to generate a multilayered structure at $96 \mathrm{~h}$ (Figure 6c). Finally, the MAS surface exhibits a layer-by-layer assembly to form a core-shell structure at $216 \mathrm{~h}$ (Figure 6d). Moreover, the monoclinic crystal length of barium peroxoborate is in the range of $10-20 \mu \mathrm{m}$ (inset of Figure 6d). It is also noted that the SEM-EDS spectrum only shows peaks of $\mathrm{Ba}, \mathrm{B}$, and $\mathrm{O}$ elements onto MAS after $216 \mathrm{~h}$ (Figure S4, Supporting Information), which depicts the formation of $\alpha-\mathrm{BaB}_{2} \mathrm{O}_{4}$ onto the MAS surface.

Figure $6 \mathrm{e}-\mathrm{h}$ shows the evolution of crystallization of the silica sand at various reaction times. Different from the MAS system, small amount of precipitate is produced onto the silica
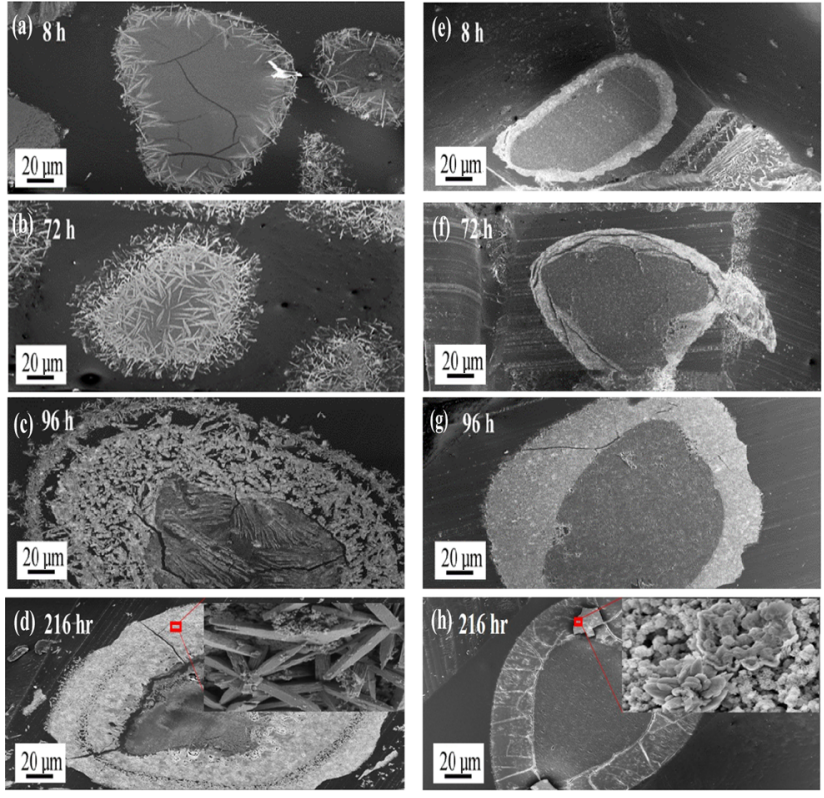

Figure 6. Cross-sectional SEM images of $(a-d)$ MAS and $(e-h)$ silica sand during boron recovery at various reaction times.

sand surface up to $72 \mathrm{~h}$. The precipitation of spherically colloidal particles onto the silica sand surface is observed at 96 $\mathrm{h}$ and then accumulates on the surface after $216 \mathrm{~h}$ of reaction. The difference in the formation mechanisms of boron precipitates between silica sand and MAS is mainly attributed to the surface functionality and specific surface area. MAS contains functional groups including $\mathrm{Si}-\mathrm{OH}^{-}$active sites and negatively charged ions of $\mathrm{T}-\mathrm{O}^{-} \ldots \mathrm{Na}^{+}$on the surface. ${ }^{29,34} \mathrm{The}$ large surface area of MAS can thus provide abundant ion exchange sites and negative charges to capture $\mathrm{Ba}^{2+}$ from the aqueous solution, which can, in turn, produce a highly crystalline barium peroxoborate $\left(\mathrm{BaB}_{2}(\mathrm{OO})_{2}(\mathrm{OH})_{4}\right)$ through a dimeric peroxoborate anion $\left(\mathrm{B}_{2}(\mathrm{OO})_{2}(\mathrm{OH})_{4}\right)^{2-}$.

According to these results, the possible mechanism of the crystallization and recovery of boron in the presence of silica sand and MAS materials is proposed. As illustrated in Scheme 2 , the crystallization of peroxoborate species in the presence of silica sand occurs from the homogeneous nucleation to produce flowerlike spherical crystals with a diameter of around $2 \mu \mathrm{m}$. The attachment of colloidal particles onto silica sand would then result in collision between nuclei and silica sands, resulting in heterogeneous nucleation and granulation. A wide variety of $\mathrm{FBC}$ reactions using silica sand as carriers for the removal of metal and nonmetal ions in aqueous solution also show similar reaction mechanism. ${ }^{41}$ Since silica sand lacks high surface area to enhance nucleation, long crystallization time is needed and a large amount of sludge would be produced during coagulation/flocculation processes. In contrast, the $\mathrm{Ba}^{2+}$-adsorbed MAS triggers the formation of barium peroxoborate more readily, followed by the nucleation and crystallization to produce a needle-like crystalloid. The needlelike crystalloid grows directly on the rough surface along with open pores of MAS. Once the active sites reach saturation, the crystalline precipitates start to grow layer-by-layer by the formation of oxo-bridge and subsequently result in the formation of a core-shell structure. 
Scheme 2. Conceptual Model of the Crystallization of Barium Peroxoborate in the COP-FBC Reactor Using Silica Sand and Mesoporous MAS Nanomaterials as Carriers

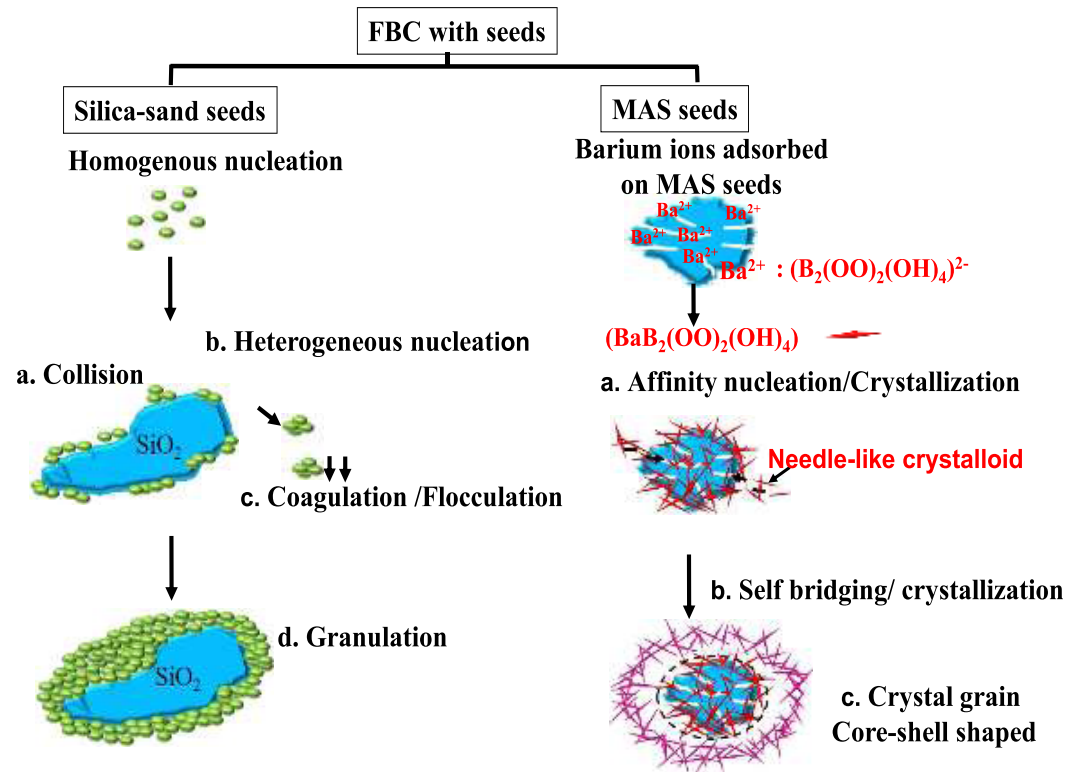

\section{CONCLUSIONS}

In this study, a functionalized mesoporous MAS nanomaterial previously developed from the TFT-LCD panel waste glass serves as a sustainable carrier for the adsorption of barium ions as well as the recovery of boron. The nonporous waste glass is transformed into mesoporous aluminosilicate nanomaterials via the cleavage of passive $\mathrm{Si}-\mathrm{O}-\mathrm{BO}$ bonds into the reactive $\mathrm{Si}-\mathrm{O}$ linkages and negatively charged ions of $\mathrm{T}-\mathrm{O}^{-} \cdots \mathrm{Na}^{+}$on the surface. A high surface area of $226 \mathrm{~m}^{2} / \mathrm{g}$ is also obtained for MAS after activation. MAS exhibits an excellent capacity for barium adsorption, and the maximum adsorption of $105 \mathrm{mg} / \mathrm{g}$ is observed, which enhances the recovery efficiency and crystallization ratio of boron by 95 and $93.4 \%$, respectively. Moreover, the possible mechanisms for the crystallization of boron-containing precipitates are elucidated. The surface functionality and large surface area of MAS trigger the crystallization of precipitates more readily and produce a layer-by-layer core-shell-type crystals rapidly. HT-XRD confirms that the crystallinity of the end-product of MAS crystallization is a hexagonal-phase $\mathrm{BaB}_{2} \mathrm{O}_{4}$, which is then converted to $\alpha-\mathrm{BaB}_{2} \mathrm{O}_{4}$ at $1050{ }^{\circ} \mathrm{C}$. Results obtained in this study clearly demonstrate a novel environmentally benign strategy for the fabrication of functionalized mesoporous aluminosilicate as the COP-FBC carrier, which can open a gateway to recover boron species from water and wastewater after the calcination of boron-containing precipitates.

\section{EXPERIMENTAL SECTION}

Chemicals. Sodium carbonate $\left(\mathrm{Na}_{2} \mathrm{CO}_{3},>99.5 \%\right), \mathrm{NaOH}$, $\mathrm{BaCl}_{2}, \mathrm{HBO}_{3}$, and $\mathrm{H}_{2} \mathrm{O}_{2}$ were purchased from Merck Co. Hydrochloric acid ( $\mathrm{HCl}, \mathrm{EL}$ grade) and nitric acid $\left(\mathrm{HNO}_{3}\right.$, EL grade) were obtained from BASF Co. All the other chemicals used in this study were of analytical grade and used as received without further purification. The waste TFT-LCD panel, an aluminoborosilicate glass, ${ }^{42}$ was from a local TFT-LCD company (Hsinchu, Taiwan). All solutions were prepared using distilled deionized water $(18.2 \mathrm{M} \Omega \mathrm{cm})$ unless otherwise mentioned.
Preparation of MAS. The MAS adsorbent was prepared from the waste TFT-LCD panel according to our previous study with minor modification. ${ }^{29}$ Briefly, TFT-LCD was ballmilled for $1 \mathrm{~h}$ and then blended with $\mathrm{Na}_{2} \mathrm{CO}_{3}$ for $10 \mathrm{~min}$ at a ratio of $1: 3$ to fabricate the functionalized mesoporous materials. It is noteworthy that the melting point of aluminoborosilicate is up to $1500{ }^{\circ} \mathrm{C}$, which can be reduced to $1000{ }^{\circ} \mathrm{C}$ with the addition of $\mathrm{Na}_{2} \mathrm{CO}_{3}$. Therefore, the resultant mixture was melted at $1000{ }^{\circ} \mathrm{C}$ for $10 \mathrm{~min}$ in a furnace. After cooling to room temperature, the resultant material was acid-washed with $1.0 \mathrm{~N} \mathrm{HCl}$ repeatedly until the solution $\mathrm{pH}$ was around 7 . Finally, the obtained mesoporous aluminosilicate nanomaterial, denoted as MAS, was calcined in the furnace at $600{ }^{\circ} \mathrm{C}$ for $6 \mathrm{~h}$ and then stored in a desiccator for further use.

Characterization of Silica Sand and MAS. The pore texture and surface area of silica sand, the commercial carrier commonly used in the COP-FBC process, and MAS were characterized by $\mathrm{N}_{2}$ adsorption-desorption isotherm using a micromeritics system model ASAP 2420 surface area analyzer over a relative pressure $\left(P / P_{0}\right)$ range of $0.01-0.99$ at $77 \mathrm{~K}$. The material was degassed at $150{ }^{\circ} \mathrm{C}$ for $6 \mathrm{~h}$ in a vacuum to remove moisture prior to analysis. The specific surface area $\left(S_{\mathrm{BET}}\right)$ was determined over the $P / P_{0}$ range of $0.05-0.2$ using the Brunauer-Emmett-Teller (BET) equation. The total pore volume $\left(V_{\mathrm{t}}\right)$ was calculated at a relative pressure of 0.989 . Moreover, the pore size distribution was analyzed by the Barrett-Joyner-Halenda model.

The surface morphology as well as the cross-sectional image of aluminosilicate materials was examined by field-emission scanning electron microscopy (Zeiss LEO 1530 FE-SEM) coupled with energy-dispersive X-ray spectroscopy (EDS) (Bruker, XFlash Dector 5010) at $20 \mathrm{kV}$ and field emission transmission electron microscopy (FE-TEM, JEOL JEM2100F/OXFORD X-Max 80T) at $200 \mathrm{kV}$. The cross section of aluminosilicate materials was prepared using a rotary microtome (Leica Ultracut, Germany). Moreover, the histogram of MAS was determined by counting the particle size from the FE-TEM image. The crystallinity was identified by 
using a Bruker D8 advanced X-ray diffractometer (XRD) with a $\mathrm{Cu} \mathrm{K} \alpha$ radiation $(\lambda=1.5405 \AA)$ at the voltage and current density of $40 \mathrm{kV}$ and $40 \mathrm{~mA}$, respectively. The change in chemical species of element in MAS nanomaterials was analyzed by a ESCA PHI 1600 X-ray photoelectron spectrometer (XPS, Physical Electronics, Eden Prairie, MN) using an $\mathrm{Al} \mathrm{K} \alpha \mathrm{X}$-ray source at $1486.6 \mathrm{eV}$. The crystalline structure of boron-containing precipitate was determined by high-temperature X-ray diffraction (HT-XRD) (Multiflex, Rigaku, Tokyo, Japan) with a $\mathrm{Cu} \mathrm{K} \gamma$ radiation at $40 \mathrm{kV}$ and $40 \mathrm{~mA}$. The XRD patterns of the precipitate were recoded from 100 to $700{ }^{\circ} \mathrm{C}$ in air on a Pt stage. The Raman spectra of crystal functional were recorded by a Bruker Senterra microRaman spectrometer equipped with an Olympus BX 51 microscope and a DU420-OE CCD camera. The functional groups of aluminosilicate-based nanomaterials were determined with a Horiba FT720 Fourier transformation infrared (FTIR) spectrophotometer to confirm the functional groups of the as-prepared MAS nanomaterials.

Adsorption of Barium lons by MAS. The adsorption of barium ions by the as-prepared MAS was performed in batch experiments. After the addition of $1 \mathrm{~g} / \mathrm{L}$ the as-prepared MAS into $100 \mathrm{~mL}$ of solutions containing $10-300 \mathrm{mg} / \mathrm{L}$ barium ions at $\mathrm{pH} \mathrm{5}$, the suspensions were incubated isothermally at $25{ }^{\circ} \mathrm{C}$ on a reciprocating thermostat water bath shaker at 150 $\mathrm{rpm}$ for $24 \mathrm{~h}$ in the dark. Appropriate amount $(1 \mathrm{~mL})$ of solution was sampled at the specific intervals and the solution was filtrated by $0.45 \mu \mathrm{m}$ filters to separate liquids and solids. The initial and final concentrations of barium ions in solutions were measured by an inductively coupled plasma-optical emission spectrophotometer (ICP-OES, iCAP-7400, Thermo Fisher).

COP-FBC Experiments. The recovery of boron by the assynthesized MAS and the commercial silica sand were studied in COP-FBC experiments. As shown in Figure S5 (Supporting Information), $50 \mathrm{~g} / \mathrm{L}$ of the as-synthesized MAS and silica sand was added into each COP-FBC column. Three different synthetic solutions containing boron, barium, and $\mathrm{H}_{2} \mathrm{O}_{2}$ at flow rates of 15,15 , and $0.7 \mathrm{~mL} / \mathrm{min}$, respectively, were transferred into the mixture separately to yield the $\left[\mathrm{H}_{2} \mathrm{O}_{2}\right] /[\mathrm{B}]$ and $[\mathrm{Ba}] /$ [B] ratios of 2 and 1 , respectively, at $\mathrm{pH} 10.5{ }^{14}$ To monitor the change in boron concentration in the COP-FBC reactor, $100 \mathrm{~mL}$ of effluent was sampled at regular intervals and then filtrated by $0.45 \mu \mathrm{m}$ filters to separate liquids and solids. The boron concentration in effluent solutions was determined by ICP-OES. In addition, the efficiency of COP-FBC was evaluated by recovery efficiency (RE, \%) and crystallization ratio $(\mathrm{CR}, \%)$ of boron using eqs 1 and $2 .{ }^{15,43,44}$

$$
\begin{aligned}
& \operatorname{RE}(\%)=\left(1-\frac{[B]_{s} \times Q_{t}}{C_{\mathrm{B} 0} \times Q_{B-W_{B}}}\right) \\
& \mathrm{CR}(\%)=\left(1-\frac{[B]_{\mathrm{t}} \times Q_{\mathrm{t}}}{C_{\mathrm{B} 0} \times Q_{\mathrm{B}}}\right)
\end{aligned}
$$

where $[B]_{\mathrm{s}}$ and $[B]_{\mathrm{t}}$ are the boron concentrations in the effluent and carrier, respectively; $Q_{t}$ and $Q_{B}$ are the total flow rate and boron flow rate, respectively; $C_{\mathrm{B} 0}$ is the initial boron concentration; and $\mathrm{AW}_{\mathrm{B}}$ is the total amount of boron washed from TFT-LCD during activation process.

\section{ASSOCIATED CONTENT}

\section{Supporting Information}

The Supporting Information is available free of charge on the ACS Publications website at DOI: 10.1021/acsomega.9b01900.

Illustration of the experimental setup of COP-FBC; SEM images and FTIR spectrum of waste TFT-LCD material; XRD patterns of MAS; and EDS spectra of MAS (PDF)

\section{AUTHOR INFORMATION}

\section{Corresponding Author}

*E-mail: radoong@mx.nthu.edu.tw. Tel: +886-3-5726785. Fax: +886-3-5718649.

\section{ORCID}

Yoshikazu Suzuki: 0000-0002-4418-6893

Ruey-an Doong: 0000-0002-4913-0602

\section{Author Contributions}

The manuscript was written through contributions of all authors. All authors have given approval to the final version of the manuscript.

\section{Notes}

The authors declare no competing financial interest.

\section{ACKNOWLEDGMENTS}

The authors thank the Ministry of Science and Technology (MOST), Taiwan, for financial support under Grant Nos. MOST 107-2221-E-007-113-MY3 and 107-2911-I-007-302.

\section{REFERENCES}

(1) Bodzek, M. The Removal of Boron from the Aquatic Environment- State of the Art. Desalin. Water Treat. 2016, 57, $1107-1131$.

(2) Wolska, J.; Bryjak, M. Method for Boron Removal from Aqueous Solution - A review. Desalination 2013, 310, 18-24.

(3) Fang, Y.; Wang, X. Metal-Free Boron-Containing Heterogeneous Catalysts. Angew. Chem., Int. Ed. 2017, 56, 15506-15518.

(4) Hu, J.; Pu, Y.; Ueda, M.; Zhnag, X.; Wang, L. Charge-Aggregate Induced (CAI) Reverse Osmosis Membrane for Seawater Desalination and Boron Removal. J. Membr. Sci. 2016, 520, 1-7.

(5) Guan, Z.; Lv, J.; Bai, P.; Guo, X. Boron removal from aqueous solution by dasorption $-\mathrm{A}$ review. Desalination 2016, 383, 29-37.

(6) Sari, M. A.; Shankararaman, C. Mechanism of Boron Removal from Hydraulic Fracturing Wastewater by Aluminum Electrocoagulation. J. Colloid Interface Sci. 2015, 458, 103-111.

(7) Irawan, C.; Kuo, Y. L.; Liu, J. C. Treatment of Boron-Containing Optoelectronic Wastewater by Precipitation Process. Desalination 2011, 280, 146-151.

(8) Kartikaningsih, D.; Huang, Y. H.; Shih, Y. J. Electro-Oxidation and Characterization of Nickel Foam Electrode for Removing Boron. Chemosphere 2017, 166, 184-191.

(9) Dolati, M.; Aghapour, A. A.; Khorsandi, H.; Karimzade, S. Boron Removal from Aqueous Solutions by Electrocoagulation at Low Concentrations. J. Environ. Chem. Eng. 2017, 5, 5150-5156.

(10) Arias, M. F. C.; i Bru, L. V.; Rico, D. P.; Galvan, P. V. Comparison of Ion Exchange Resin Used in Reduction of Boron in Desalinated Water for Human Consumption. Desalination 2011, 278, 244-253.

(11) Bilgin Simsek, E.; Beker, U.; Senkal, B. F. Predicting the Dynamics and Performance of Selective Polymeric Resins in A Fixed Bed System for Boron Removal. Desalination 2014, 349, 39-50.

(12) Kang, J.; Tang, Y.; Gao, S.; Liu, L. One-Dimensional Controllable Cross-linked Polymers Grafted with N-Methyl-D- 
Glucamine for Effective Boron Adsorption. New J. Chem. 2018, 42, 11334-11340.

(13) Lin, J. Y.; Shin, Y. J.; Hsieh, T. Y.; Huang, Y. H. Role of Phase Transformation of Barium Perborates in the Effective Removal of Boron from Aqueous Solution via Chemical Oxo-Precipitation. RSC Adv. 2016, 6, 63206-63213.

(14) Lin, J. Y.; Shin, Y. J.; Chen, P. Y.; Huang, Y. H. Precipitation Recovery of Boron from Aqueous Solution by Chemical OxoPrecipitation at Room Temperature. Appl. Energy 2016, 164, 10521058.

(15) Vu, X. T.; Lin, J. Y.; Shih, Y. J.; Huang, Y. H. Reclaiming Boron as Calcium Perborate Pellets from Synthetic Wastewater by Integrating Chemical Oxo-Precipitation within a Fluidized-Bed Crystallizer. ACS Sustainable Chem. Eng. 2018, 6, 4784-4792.

(16) Lin, J. Y.; Song, Y. J.; Shin, Y. J.; Huang, Y. H. Solubility Products of Sparingly Soluble Barium Perborates in Aqueous Solution that Contains $\mathrm{B}(\mathrm{OH})_{3}$ and $\mathrm{H}_{2} \mathrm{O}_{2}$ at $25{ }^{\circ} \mathrm{C}$. J. Colloid Interface Sci. 2017, 505, 703-710.

(17) Shih, Y. J.; Liu, C. H.; Lan, W. C.; Huang, Y. H. A Novel Chemical Oxo-Precipitation (COP) Process for Efficient Remediation of Boron Wastewater at Room Temperature. Chemosphere 2014, 111, 232-237.

(18) Shih, Y. J.; Abarca, R. R. M.; Luna, M. D. G.; Huang, Y. H.; Lu, M. C. Recovery of Phosphorus from Synthetic Wastewaters by Struvite Crystallization in a Fluidized-Bed Reactor: Effects of $\mathrm{pH}$, Phosphate Concentration and Coexisting Ions. Chemosphere 2017, 173, 466-473.

(19) Jiang, K.; Zhou, K. G. Recovery and Removal of Fluoride from Fluorine Industrial Wastewater by Crystallization Process: A Pilot Study. Clean Technol. Environ. Policy 2017, 19, 2335-2340.

(20) Hernández-Morales, V.; Nava, R.; Acosta-Silva, Y. J.; MaciasSanchez, S. A.; Perez-Bueno, J. J.; Pawelec, B. Adsorption of Lead (II) on SBA-15 Mesoporous Molecular Sieve Functionalized with- $\mathrm{NH}_{2}$ Groups. Microporous Mesoporous Mater. 2012, 160, 133-142.

(21) Javadian, H.; Vahedian, P.; Toosi, M. Adsorption Characteristics of $\mathrm{Ni}$ (II) from Aqueous Solution and Industrial Wastewater onto Polyaniline/HMS Nanocomposite Powder. Appl. Surf. Sci. 2013, 284, 13-22.

(22) Doong, R. A.; Liao, C. Y. Enhanced Photocatalytic Activity of $\mathrm{Cu}$-Deposited $\mathrm{N}-\mathrm{TiO}_{2} /$ Titanate Nanotubes under UV and Visible Light Irradiations. Sep. Purif. Technol. 2017, 179, 403-411.

(23) Doong, R. A.; Liao, C. Y. Enhanced Visible-Light-Responsive Photodegradation of Bisphenol $\mathrm{A}$ by $\mathrm{Cu}, \mathrm{N}$-Codoped Titanate Nanotubes Prepared by Microwave-Assisted Hydrothermal Method. J. Hazard. Mater. 2017, 322, 254-262.

(24) Amato, A.; Rochetti, L.; Beolchini, F. Environmental impact assessment of different end-of-life LCD management strategies. Waste Manag. 2017, 59, 432-441.

(25) Amato, A.; Beolchini, F. End of life liquid crystal displays recycling: A patent review. J. Environ. Manage. 2018, 225, 1-9.

(26) Tsujiguchi, M.; Kobashi, T.; Utsumi, Y.; Kakimori, N.; Nakahira, A. Synthesis of Zeolite from Aluminoborosilicate Glass Used in Glass Substrates of Liquid Crystal Display Panels and Evaluation of its Cation Exchange Capacity. J. Am. Ceram. Soc. 2014, 97, 114-119.

(27) Kim, K.; Kim, K.; Hwang, J. Thin Film Transistor-Liquid Crystal Display Cullet: A Raw Material for Production of Commercial Soda Lime Silicate Glasses. J. Cleaner Prod. 2014, 79, 276-282.

(28) Li, X.; Gao, S.; Xing, P.; Dong, K.; Gao, B.; Feng, Z. Recovery and reutilization of high-quality boron carbide from sapphire wafer grinding-waste. J. Environ. Manage. 2018, 224, 106-112.

(29) Tsai, C. K.; Doong, R. A.; Hung, H. Y. Sustainable Valorization of Mesoporous Aluminosilicate Composite from Display Panel Glass Waste for Adsorption of Heavy Metal Ions. Sci. Total Environ. 2019, 673, 337-346.

(30) Jang, H.; Jeon, S.; So, H.; So, S. Properties of Different Particle Size of Recycled TFT-LCD Waste Glass Powder as A Cement Concrete Binder. Int. J. Precis. Eng. Manuf. 2015, 16, 2591-2597.
(31) Dutta Chowdhury, A.; Doong, R. A. Highly Selective and Selective Detection of Nanomolar Ferric Ions Using Dopamine Functionalized Graphene Quantum Dots. ACS Appl. Mater. Interfaces 2016, 8, 21002-21010.

(32) Ning, C.; Pejman, H.; Meng, X.; Lin, C. S.; McKay, K. G. Valorization of an Electronic Waste-Derived Aluminosilicate: Surface Functionalization and Porous Structure Tuning. ACS Sustainable Chem. Eng. 2016, 4, 2980-2989.

(33) Mikhailova, O.; del Campo, A.; Rovnanik, P.; Fernández, J. F.; Torres-Carrasco, M. In Situ Characterization of Main Reaction Products in Alkali-Activated Slag Material by Confocal Raman Microscopy. Cem. Concr. Compos. 2019, 99, 32-39.

(34) McGrail, B. P.; Icenhower, J. P.; Shuh, D. K.; Liu, P.; Darab, J. G.; Baer, D. R.; Thevuthasen, S.; Shutthanandan, V.; Engelhard, M. H.; Booth, C. H.; Nachimuthu, P. The Structure of $\mathrm{Na}_{2} \mathrm{O}-\mathrm{Al}_{2} \mathrm{O}_{3}-\mathrm{SiO}_{2}$ Glass: Impact on Sodium Ion Exchange in $\mathrm{H}_{2} \mathrm{O}$ and $\mathrm{D}_{2} \mathrm{O}$. J. NonCryst. Solids 2001, 296, 10-26.

(35) Hadi, P.; Barford, J.; Mckay, G. Toxic Heavy Metal Capture Using a Novel Electronic Waste-Based Material- Mechanism, Modeling and Comparison. Environ. Sci. Technol. 2013, 47, 82488255.

(36) Doong, R. A.; Tsai, C. W. Synergistic Effect of Cu Adsorption on the Enhanced Photocatalyst Degradation of Bisphenol a by $\mathrm{TiO}_{2} /$ Titanate Nanotubes Composite. J. Taiwan Inst. Chem. Eng. 2015, 57, 69-76.

(37) Jung, K. W.; Lee, S. Y.; Choi, J. W.; Lee, Y. J. A facile one-pot hydrothermal synthesis of hydroxyapatite/biochar nanocomposites: Adsorption behavior and mechanisms for the removal of copper (II) from aqueous media. Chem. Eng. J. 2019, 369, 529-541.

(38) Mu, W.; Du, S.; Yu, Q.; Li, X.; Wei, H.; Yang, Y. Improving Barium Ion Adsorption on Two Dimensional Titanium Carbide by Surface Modification. Dalton Trans. 2018, 47, 8375-8381.

(39) Lin, J. Y.; Shih, Y. J.; Chen, P. Y.; Huang, Y. H. Potential OxoPrecipitation (COP) for Remediating Wastewater with a High Boron Concentration Using $\mathrm{H}_{2} \mathrm{O}_{2} / \mathrm{Ba}(\mathrm{OH})_{2}$ at Room Temperature. Energy Procedia 2014, 61, 349-352.

(40) Walrafen, G. E.; Krishnan, P. N.; Hokmabadi, M. D.; Griscom, C.; Munro, R. G. Surface Raman Scattering from Effervescent Magnetic Peroxyborates. J. Chem. Phys. 1982, 77, 3840-3846.

(41) Chen, C. S.; Shih, Y. J.; Huang, Y. H. Remediation of Lead( $\mathrm{Pb}(\mathrm{II}))$ Wastewater Through Recovery of Lead Carbonate in as Fluidized-Bed Homogeneous Crystallization (FBHC) System. Chem. Eng. J. 2015, 279, 120-128.

(42) Tsujiguchi, M.; Kobashi, T.; Utsumi, Y.; Kakimori, N.; Nakahira, A. Synthesis of FAU Zeolite from Aluminoborosilicate Glass and Elution Behavior of Glass Components. J. Ceram. Soc. Jpn. 2014, 122, 104-109.

(43) Priambodo, R.; Shih, Y. J.; Huang, Y. H. Phosphorus Recovery as Ferrous Phosphate (Vivianite) From Wastewater Produced in Manufacture of Thin Film Transistor-Liquid Crystal Displays (TFTLCD) by a fluidized bed crystallizer (FBC). RSC Adv. 2017, 7, 40819-40828.

(44) Villa-Gomez, D.; Ababneh, H.; Papirio, S.; Rousseau, D. P. L.; Lens, P. N. L. Effect of Sulfide Concentration on the Location of the Metal Precipitates in Inversed Fluidized Bed Reactors. J. Hazard. Mater. 2011, 192, 200-207. 